\title{
Enhancing Leadership, Management and Governance Competencies for Performance Improvements at Primary Health Care Entities in Ethiopia: A Quasi-Experimental Study Design
}

Mesele Damte Argaw ( $\nabla$ mdamte5@gmail.com )

JSJ Research \& Training Institution, Inc. https://orcid.org/0000-0002-9558-6619

Binyam Fekadu Desta

JSI Research \& Training Institute Inc

Sualiha Abdlkader Muktar

JSI Research \& Training Institute Inc

Nurhan Tewfik

Ethiopia Ministry of Health

Bekele Belayhun Tefera

Pathfinder International

Wondwosen Shiferaw Abera

JSI Research \&Training Institute Inc

Temesgen Ayehu Bele

Ethiopia Ministry of Health

Selahadin Seid Buseir

Ethiopia Ministry of Health

Deirdre Rogers

JSI Research \& Training Institute Inc

Kristin Eifler

JSI Research \& Training Institute Inc

Research

Keywords: Leadership, Management, and Governance, Performance Improvement, Training, Ethiopia

Posted Date: March 20th, 2020

DOI: https://doi.org/10.21203/rs.3.rs-18051/v1

License: (9) This work is licensed under a Creative Commons Attribution 4.0 International License.

Read Full License 

Mesele Damte Argaw1,*, Binyam Fekadu Desta', Sualiha Abdlkader Muktar', Nurhan Tewfik², Bekele Belayhun Tefera ${ }^{3}$, Wondwosen Shiferaw Abera', Temesgen Ayehu Bele4, Selahadin Seid Buseir², Deirdre

7 Rogers ${ }^{5}$, Kristin Eifler ${ }^{5}$

IUSAID Transform: Primary Health Care, JSI Research \& Training Institute, Inc.

10 P.O. Box 1392 code II I0, Addis Ababa, Ethiopia

11 2Federal Ministry of Health, Human Resource Development Directorate Addis Ababa, Ethiopia

12 3USAID Transform: Primary Health Care, Pathfinder International, Addis Ababa, Ethiopia

13 4Federal Ministry of Health, Health Extension and Primary Health Services Directorate, Addis Ababa,

14 Ethiopia

15 5JSI Research \& Training Institute, Inc., Boston, USA

\section{*Corresponding author}

E-mail address: mdamte5@gmail.com; mesele_damte@et.jsi.com

21 E-mail address:

22 MDA:*mdamte5@gmail.com

BFD: binyam_desta@jsi.com

24 SAM: sualiha_abdikader@et.jsi.com

25 NT: nurhan.tewfik@moh.gov.et

26 BBT: BBelayihun@pathfinder.org

27 WSA: wondwosen_shiferaw@et.jsi.com

28 TAB: temesgen.ayehu@moh.gov.et

29 SSB: selha.99@gmail.com

30 DR: deirdre_rogers@jsi.com

31 KE: kristin_eifler@jsi.com 


\section{Abstract}

Background: Leadership, management, and governance (LMG) interventions play a significant role in improving management systems, enhancing work climate, and creating responsive health systems. The Federal Ministry of Health with the support of USAID Transform: Primary Health Care project, cascaded its basic LMG trainings and interventions to primary health care staff. The purpose of this evaluation was to measure the changes observed on performance improvement at primary health care entities after implementing the interventions for one year. The results of this research will help policy makers, program managers, and implementers to make informed decisions in the area of performance improvement.

Methods: The study used a quasi-experimental pre-post survey design to assess the changes observed as a result of LMG in performance management at primary health care entities. It was conducted from August 28, 2017 to September 30, 2018 in Amhara, Oromia, Tigray, and Southern Nations, Nationalities and Peoples Regions. The data was collected through document review and interviewer and selfadministered questionnaires across 136 health facilities, in which there are 293 health workers who attended the LMG training; and 333 health workers who did not attend the training. In addition, training records were reviewed to capture change in knowledge and skill through pre-post training and, baseline and end-line performance improvement project achievements, respectively. The data were analyzed using SSPS IBM V 20.

Results: The response rates were $100 \%$ for staff who attended the training; and $87 \%$ for staff who did not attend the training. Of those who attended the training, $235(80.9 \%)$ and $252(86 \%)$ trainees scored above $70 \%$ on post-test, and $80 \%$ or more achieved the desired measurable results of their performance improvement projects. Using the above-mentioned criteria, composite scores were compiled from posttest and performance improvement project results. The result showed that 70\% (205/293) of basic LMG trainees completed the course. As a result of the LMG trainings, management systems, work climate, and responsiveness of the health system to challenges significantly improved $(p<0.00 \mathrm{I})$. Because of the leadership projects, an additional 2,290.3 units of health service coverage were gained.

Conclusions: The performance of the primary health care entities was significantly improved as a result of enhanced knowledge and skills through LMG trainings, and leadership projects implemented at primary health care entities. We recommend providing LMG trainings for more health workers and managers working at primary health care entities to accelerate implementation of prioritized health sector interventions helpful to achieving the Sustainable Development Goals as a global target. Evaluation of effectiveness and efficiency of the basic LMG training package is recommended.

Keywords: Leadership, Management, and Governance; Performance Improvement; Training; Ethiopia. 
I. Introduction

According to the World Health Organization (WHO), a health system is defined as 'all organizations, people, and actions whose primary intent is to promote, restore or maintain health.' The WHO health systems framework identifies six essential building blocks, or key functions: service delivery; health workforce; information; medical products, vaccines, and technologies; financing; and leadership and governance. To strengthen a health system, in addition to managing the interactions among the six building blocks, each building block needs to be strengthened [I]. However, lack of "leadership. governance and managerial capacity" at all levels of the health systems was identified as a major constraint to scale up proven and affordable services in low and middle-income countries [2] [3]. Ethiopia's Federal Ministry of Health (FMOH) defines four pillars of excellence in health namely, service delivery; quality improvement and assurance; leadership and governance; and health system capacity to achieve its vision of "healthy, productive and prosperous Ethiopians." [4] Leadership, management, and governance (LMG) interventions thus play a significant role in improving management systems, enhancing work climate, and creating responsive systems that are more accessible, with better quality and expanded service availability at affordable cost [5] [6].

USAID funds the five-year (20I7-202I) Transform: Primary Health Care (PHC) project, which is led by Pathfinder International and implemented by a consortium of international and local development partners (JSI Research \& Training Institute, Inc. [JSI], Abt Associates Inc., Malaria Consortium, EnCompass, and Ethiopian Midwives Association). During its first year, the project provided technical support in 300 woredas (districts) and has since expanded to 360 woredas in four agrarian regions, (Amhara, Oromia, Southern Nation Nationalities and Peoples [SNNP], and Tigray) in Ethiopia. The project aims to contribute to the accomplishments of the Government of Ethiopia's Health Sector Transformation Plan and to prevent maternal and child death [7].

Ethiopia adopted and implemented several LMG trainings to strengthen health systems and build services that are accessible to more people by developing inspired leaders, sound management systems, and transparent practices within and among individuals, networks, organizations, and governments. Some of these training modalities are: Leadership for strategic information [8] - a year-long training for policy makers, and strategic decision makers; Leadership, management, and governance [9] - a set of three different trainings for policy makers and district, health center and hospital managers implemented through four workshops completed over 6-9 months; Primary health care unit management development program [10] - which consisted of four workshops over 6-12 months per district; and Transformational leadership program [I I] - facilitated by the International Institute of Primary Health Care in Ethiopia for primary health care managers and program directors over five days.

Data reported in this study cover the performance improvements observed as a result of implementing the basic LMG training and interventions at primary health care entities, which is a part of a comprehensive evaluation conducted to determine the effectiveness, and efficiency of the training. The need to redesign training content and approach will be considered to publish in peer reviewed journal subsequently. The aim of this study was to measure the changes in health service performance improvements as a result of interventions using the modified Kirkpatrick (1994) conceptual map of training evaluation [12] through implementation over the course of a one-year period. 


\section{I Study Design}

This study employed a quasi-experimental pre-post design [13], [14], [15] and was conducted between August 28, 2017 and September 30, 2018 in Amhara, Oromia, SNNP, and Tigray Regions of Ethiopia. Kirkpatrick (1994) model is well known to analyses and evaluate training and educational programs. In addition, it considers different style of trainings, both formal \& informal, and useful to determine aptitudes based on its four levels of criteria [16]. Therefore, for this study a modified Kirkpatrick (1994) model of training evaluation [12] [17] was used as a guiding framework for the data collection, analysis, and interpretation (Fig I).

\subsection{Study Setting}

USAID Transform: PHC project is implemented in four agrarian Regions (Amhara, Oromia, SNNP, and Tigray) of Ethiopia (figure 2). According to the Health and Health-Related Indicators of Ethiopia 2016, the 77 million inhabitants of these regions represent $85.9 \%$ of the national population [18]. Each region is subdivided into zones and woredas which are the smallest government administration units. The project works in 300 (43.7\%) woredas; 76 (45.2\%) of which are in Amhara; I 35 (44.8\%) in Oromia; 70 (42.4\%) in SNNP; and 19 (36.5\%) in Tigray Regions. The four regions have 76 primary hospitals; I,53 I health centers; and 7,562 health posts [19]. In 2017, through the direct support of the project, 24 (8.0\%) of districts had LMG trained healthcare workers and managers at all primary health care entities [19].

\section{Adoption of Leadership, Management and Governance Interventions}

Based on the lessons from and national experience, the USAID Transform: PHC project developed block and segmented training packages with six to nine-month leadership projects to reach staff at primary health care facilities (Additional file I). The project developed and implemented its LMG interventions using nationally endorsed course ${ }^{1}$ materials that allowed trainees to earn 78 continuous education units upon completion [9]. The five course modules include: (I) Introduction to Health Systems; (2) Introduction to Leadership, Management and Governance; (3) Improving Performance through Enhanced Leadership, Management and Governance; (4) Resource Management; and (5) Health Service Delivery Management. Each module consisted of units, sessions and sub-sessions designed to achieve desired competencies. These practices consist of: four leading practices (scanning; focusing; aligning and mobilizing; inspiring); four managing practices (planning; organizing; implementing; monitoring and evaluating); and five governing practices (cultivating accountability; engaging stakeholders; setting shared goals; stewarding resources; and continuous governance enhancement).

\section{Basic LMG Trainings and coaching interventions}

USAID: Transform Primary Health Care facilitated the two training modality option blocks (all at once) and segmented blocks (broken into a certain number of days over a period of time) for each of the five course modules. From June $8^{\text {th }}$ - September $30^{\text {th }}, 2017$, ten block and fourteen segmented basic LMG trainings were facilitated and baseline measurements were taken. The details of participants in each category and region are presented in Table $\mathrm{I}$.

I EFMOH.2017. Leadership, Management and Governance In-service Training Manual for Health Managers at Hospital and Health Centers. Addis Ababa: EFMOH. The LMG training packages have been developed and approved by the Federal Ministry of Health. 
Based on the national course syllabus, the LMG core teams developed and implemented performance improvement projects at their facilities for six-to-nine months, during which each team received three or four on-site coaching sessions [9]. The intended outcomes of the leadership projects included increasing the number of institutional deliveries; the proportion of modern contraceptive users; and the number of primary health care facilities that meet Ethiopian Health Service Transformation Guidelines standards (Additional file 2). The performance improvement or leadership projects also helped trainees use LMG training concepts to solve challenges at work. After implementation, each performance improvement or leadership project was assessed against its intended targets. From 25th December 2017 - 30th March 2018, the assessment team, comprised of LMG experts from participating in-service training institutions, ZHDs, and the USAID Transform: PHC project, appraised the performance of each team and helped the core LMG team present its findings and results in a knowledge sharing events.

\subsection{Target Population}

The study targeted two groups of the population; namely, LMG trained health workers, and non- trained health workers employed in four intervention targeted regions. Trained health workers and managers with the support of USAID Transform: PHC project were targeted to measure their knowledge and skills on LMG practices gained as a result of the interventions. LMG trained and non-trained health workers perceived changes in management system, work climate and responsiveness of the health systems for new challenges were measured before and after intervention.

\subsection{Eligibility Criteria}

All study participants work in USAID Transform: PHC project led LMG intervention targeted primary health care entities. All basic LMG trainees and non-trained staff in the public health sector who volunteered to participate and those that had completed at the pre-post training interviews were targeted. However, health workers in facilities not targeted for LMG intervention, health workers who did not volunteer to participate and health workers who had not completed the pre-post interviews were exempted from in the study.

\subsection{Sampling Size and Sampling}

All twenty-four LMG intervention targeted woredas were purposively selected and three different sampling methods were used to calculate the desired sample sizes.

The first sample size (n) for number of LMG trainees was calculated using Slovin's formula [20]:

$\mathrm{n}=\mathrm{N} / \mathrm{I}+\mathrm{N}(\mathrm{e})^{2}$

where:

$\mathrm{n}=$ designates sample size for the study

$\mathrm{N}=$ designates total number of employees

$\mathrm{e}=$ designates maximum variability or margin of standard error at $95 \%$ confidence interval

$\mathrm{I}=$ designates the probability of the event occurring 
Therefore:

$\mathrm{n}=\mathrm{N} / \mathrm{I}+\mathrm{Ne}^{2} \mathrm{n}=\left[555 / \mathrm{I}+555 *(0.05)^{2}\right]$

$n=555 / 2.38=233$; and 25\% (non-response, refusal, and dropout) makes the sample size of 293 [2I].

The sample size was allocated based on the number of trainees in each intervention woreda.

The second sample size (ni) for non-trained staff was calculated using single population proportion formula:

Where $n i$ is sample size, $P$ is the proportion of LMG non-trained staff who have the desire knowledge on thirteen practices, and $d$ is the margin of error.

In addition, the following assumption was used: Since $P$ is $0.50 \%(p=0.50, q=0.50)$, allowing $5 \%$ for expected margin of error $(d)$ with $95 \%$ confidence level $\left(Z_{\alpha / 2}=1.96\right)$, the required sample size $n i$ is 384 . The sample size was distributed based on population proportion to size of LMG trainees in targeted health facilities.

\subsection{Data Collection}

The data were collected from basic LMG trainees and non-trained staff working in intervention primary health care entities using interviewer-administered and self-administered structured questionnaires, respectively. The questionnaires were prepared after thorough review of relevant literature and the National Leadership, Management, and Governance in-service training materials for hospital and health center managers [3] [9] [23].

Sixteen data collectors, each with clinical, health management, social science, or public health training were recruited. Data collectors and supervisors were trained on the ethical principles, data collection tools, and interviewing techniques. Before the actual data collection started, all tools were piloted in USAID Transform: PHC project-supported woredas and amended accordingly.

Data were collected to monitor post training self-efficacy, cognitive learning and training performances. The pre-post measurements were designed to capture the knowledge and skills of health workers on thirteen Leadership, Management and Governance practices. Similarly, the baseline and end-line Performance Improvement project achievements were rated with trained LMG coaches. Certified LMG training facilitators and project staff supervised all data collectors. The principal investigators and supervisors checked completeness and consistency of each filled questionnaire and made corrections on a daily basis. 
The questionnaires had three sections: I) instruction and consent forms to guide interviewers; 2 ) sociodemographic characteristics of participants; and 3) document review using data abstraction for scores of each trainee captured during classroom pre-posttests, and performance improvement project baseline and end-line achievements.

\subsubsection{Health System Strengthening survey}

Eighteen questions with a 10-point Likert Scale [24] were used to measure responses to statements presented to express to strengthened management system ( 9 items); enhanced work climate (5 items); and responsiveness or capacity of health system to overcome new challenges (4 items). The sample questionnaire for each category is presented in the below boxI. To measure the changes on LMG practices of trainees were made as a self-assessment tool dedicated their perceived practices before and after the Basic LMG trainings offered. The respondents for this tool were LMG trainees and non-trained health workers in the intervention area's primary health care entities. These were adapted from Clinical Leadership Competency Framework of the United Kingdom as cited in Mutale et al. (2017) [3]. The questionnaire was developed in English and translated into local languages (i.e., Amharic, Afan Oromo, and Tigrigna), then translated back to English. The tool was pre-tested for reliability and validity before being used in the current study [25].

Prior to administration, reliability and validity of the data collection tools were assessed. The data were analyzed using SPSS IBM Version 20 [26]. The tools' internal reliability was assessed using Cronbach's alpha values. According to Hals (1986), if the Cronbach's alpha value score is more than 0.6, the scale can be considered reliable. The tools have 18 questions in three categories; namely, nine questions on strengthened management system, five questions on enhanced work climate, and four questions on capacity to respond to change. The reliability test results were 0.839 for work climate, 0.895 for strengthened management systems, and 0.886 for capacity to respond to changes, which showed the scale used was internally consistent and reliable.

A statistical test using multi-collinearity analysis through determining variance inflation factor (VIF) was run to check the tools' divergent validity [14]. According to Menard (1995), if the VIF reported value exceeds 10, it implies the associated regression coefficients are poorly estimated because of multicollinearity [27]. In this pilot study, the collinearity test VIF results for work climate was I.0I8, 2.94 for strengthened management systems, and 6.443 for capacity respond to new change, no VIF value exceed I0. Hence, there was no observed serious multi-collinearity affecting the regression coefficient.

Descriptive statistics were employed using frequencies, tables, and graphs. In addition, linear regression was used to test the relationship among each dependent and independent variable. Paired sample t-test and analysis of variance (ANOVA) were conducted to check whether there were significant differences in mean values by individual and organizational characteristics. Multivariable linear regression analysis was used to identify the predictors of LMG training effectiveness.

\subsection{Ethical Considerations}

Ethical clearance was obtained from regional institutional review boards. Before starting data collection, permission and support letters were collected from four regional state health bureaus. Data were 
collected after getting full informed consent from every participant. Privacy, anonymity, and confidentiality were maintained throughout the data collection, analysis, and report writing activities.

3. Results

Table 2 presents the statistical summary of the socio-demographic data collected from trainees. Onehundred and-three trainees (35.2\%) were recruited from SNNPR; $62.5 \%$ of study participants (183) are between 26 and 35 years of age; the mean age with standard deviation (SD) was $29.9 \pm 6.9$ years. The majority $(222 / 75.8 \%)$ of study participants were male. Seventy $(58.0 \%)$ were nurses who had worked in the profession for an average of 7.6 years.

Table 3 below presents the socio-demographic characteristics of non LMG trained staff in selected health facilities. The majority $38.4 \%$ were selected from Oromia region, and $78.7 \%$ of participants age category lies within 26- 35 years.

One-hundred-thirty-six randomly selected health facilities from 2 I (I5.6\%) Tigray, 35 (25.2\%) Oromia, 37 (27.4\%) Amhara and 43 (31.9\%) SNNP regional states were included in the study. One-hundred-and eleven (82.2\%) were health centers, I 2 (8.9\%) were primary hospitals, II were District Health Offices and 2 were Zone Health Department. Fifty-eight facilities were in high-performing districts (Table 3).

\section{I. Knowledge change Pre- and Post-training}

The LMG trainees' knowledge mean pretest score with SD was $44.97 \% \pm 15.50 \%$. The post-test score was $78.11 \% \pm 14.22 \%$, which showed a significant gain in knowledge at post-test with $t=-35.99, \mathrm{df}=292$, $\mathrm{P}<0.00 \mathrm{I}$. In this study, $80.9 \%$ (237) of trainees scored greater or equal to $70 \%$ on post-test.

\subsection{Performance change Baseline and End-line survey}

Of I 36 performance improvement projects, 53 (38.9\%) were developed on delivery service. Twenty-five (18.5\%) focused on family planning and 25 (18.5\%) on health systems strengthening (Figure 3). All I36 core LMG teams were assessed; the performance improvement mean baseline score with SD was 38.35 \pm 24.79 units and mean achieved end-line desired measurable result with SD was $52.22 \pm 26.23$ units. The majority (252/86.0\%) of trainees completed their performance improvement projects and achieved $80.0 \%$ or more of their desired measurable results. As a result of these projects, 2,290.6 units of desired measurable results were gained. The average net gain by each entity was 16.55 ( $95 \% \mathrm{Cl}: 12.26,20.84)$ with SD ( \pm 17.59$)$ units. The result gained, with paired sample t-test $t=-12.28, d f=292, p<0.001$, was statistically significant.

The technical support ensured sustainability through the development of new performance improvement projects by trainees; as of September 2018, 33.3\% (45/I35) core LMG teams had developed new performance improvement projects for the next six months. Of the new projects, 18 (40\%) focus on health systems strengthening; 12 (26.6\%) on maternal and newborn health; 10 (22.2\%) on family planning; 4 (8\%) on community-based health insurance $(\mathrm{CBHI})$; and I (2\%) TB screening. 
Figure 4 depicts the proportion of trainees who scored $>70 \%$ in post-test and $>80 \%$ in leadership projects. The result of the theory showed that trainees from block LMG training had a higher score, with a borderline significant difference at $X^{2}=5.6 \mathrm{I} . \mathrm{P}=0.06$. Similarly, the result of the end-line performance improvement or leadership project evaluation showed that trainees of the block LMG had a higher score, with a statistically significant difference at $X^{2}=8.32$. $P=0.01$. Certification showed that more block LMG trainees completed the course than segmented trainees, with a statistically significant difference at $X^{2}=7.16$. $P=0.02$.

\subsection{Health system improvement}

Tables 8 and 9 depict health system improvements observed as result of basic LMG trainings. Trainees assessed and measured the level of management system improvements, enhanced work climate, and responsiveness of the health system to face new challenges. The mean perceived pre and post-training scores on strengthening management system with SD was $5.75 \pm 233$ and $8.03 \pm 1.44$, respectively. This perceived assessment revealed a significant improvement at post-training, with $\mathrm{t}=-18.54, \mathrm{df}=292$, $\mathrm{P}<0.00 \mathrm{I}$. Similarly, the average pre-and post-training scores on enhanced work climate were reported with SD of $5.75 \pm 1.85$ and $7.88 \pm 1.64$, respectively. This result showed a statistically significant improvement at post-training, with $\mathrm{t}=-23.97, \mathrm{df}=292, \mathrm{P}<0.00 \mathrm{I}$. Moreover, the average pre-and posttraining scores on capacity to respond to a new change (responsiveness) with SD were $5.64 \pm 1.92$ and $7.8 \mathrm{I} \pm 1.62$, respectively. This result showed a statistically significant improvement at post-training, with $\mathrm{t}=-22.83, \mathrm{df}=292, \mathrm{P}<0.00 \mathrm{I}$. The overall pre and post-training health system improvement scores were $5.69 \pm 1.73$ and $7.93 \pm 1.43$, respectively. The score showed a statistically significant improvement with $\mathrm{t}=-26.09, \mathrm{df}=292, \mathrm{P}<0.00 \mathrm{I}$ (Tables 4).

Similarly, 333 non-trained staff were asked to measure their work climate, management systems, and health systems responsiveness to challenges in their respective health facilities before and after their peers participated in LMG training. The mean pre and post-training scores on strengthening management system with SD was $6.34 \pm 1.87$ and $7.35 \pm 1.44$, respectively. This perceived assessment revealed a significant improvement at post-training, with $\mathrm{t}=-1 \mathrm{I} .99, \mathrm{df}=332, \mathrm{P}<0.00 \mathrm{I}$. Similarly, the average pre-and post-training scores on enhanced work climate were reported with SD of $6.12 \pm 1.96$ and $7.38 \pm 1.82$, respectively. This result showed a statistically significant improvement at post-training, with $t=-16.49, d f=332, P<0.00 I$. Moreover, the average pre-and post-training scores on capacity to respond to a new change (responsiveness) with SD were $6.19 \pm 1.95$ and $7.61 \pm 1.90$, respectively. This result showed a statistically significant improvement at post-training, with $t=-17.58, \mathrm{df}=332, \mathrm{P}<0.00 \mathrm{I}$. The overall pre- and post-training health system improvement scores were $6.24 \pm 1.76$ and $7.5 \mathrm{I} \pm 1.74$, respectively. The score showed a statistically significant improvement with $t=-17.09, \mathrm{df}=332, \mathrm{P}<0.00 \mathrm{I}$ (Tables 4). 


\section{Discussion}

This quasi-experimental pre-post study is dedicated to evaluating USAID Transform: PHC projectsupported basic leadership, management, and governance training and interventions which was cascaded to primary health care workers and managers in four regional states of Ethiopia. The LMG training included didactic theoretical-based classroom trainings implemented either as a block or sequential training combined with subsequent implementation of performance improvement projects for six-to-nine months at trainees' place of employment [9]. The knowledge and skills gained as a result of these trainings were demonstrated through pre-test, post-test, baseline, and end-line performance improvement project scores and continuing development of performance improvement projects in the health systems. The results revealed that the LMG training and interventions had a positive impact on the performance of I 36 primary health care entities. Furthermore, more than one third of trainees had developed subsequent performance improvement projects. Hence, trainees confirmed the long-term effects of capacity enhancement on performance of the health system. The result demonstrated the need to enhance the LMG competencies among health workers and managers, whose pre-service professional education inclined to clinical care with limited coverage to the Leadership, Management and Governance practices. Hence, without building the LMG competencies of health workers and managers, the health system may not deliver quality essential health services to the community. This in turn limit their performance level and then lead to further frustration of health workers and health service mangers. This was in keeping with the Uneke et al. (2012) finding in Nigeria, where training significantly increased policy makers' understanding of leadership and governance and improved human resources development, collaboration, system design, and accountability [28]. Similarly, the finding was concurred with Mutale et al (2017) report on the catalyzing effect of Leadership and management training in health system strengthening in Zambia [3].

The conceptual map and assumption of the LMG training was: enhancing knowledge and skills on leading, managing and governing practices of health workers and managers at primary health care entities would significantly improve the performance of individuals, teams, organizations and health systems for better health outcomes [9] [29]. In this study, the performance of basic LMG trainees were assessed by measuring trainees' post-training knowledge, skills, and behavioral patterns within primary health care facilities [30]. The majority 235 (81\%) and 252 (86\%) of trainees scored above $70 \%$ on post-test and $80 \%$ or more on DMRs of their performance improvement projects, respectively. In addition, both trained and non-trained staff appreciated the positive impact of the knowledge and skills acquired by trainees on improving the management systems, work climate, and health system responsiveness to new challenges in their workplace. This finding was consistent with Packard et al (20I5) reported after leadership development intervention the on-job performance participants and their supervisors were improved and level of self-efficacy were significantly increasing over time [3I].

387 The evaluation indicated that trainees contributed to the improvement of primary health care service 388 coverage over 12 months of LMG interventions. This result was also attributed to the implementation of multi-faceted LMG intervention, which ranged from classroom training to leadership-project development and implementation. The performance improvement was observed as improved management system, and

391 work climate in the study area. The findings also concur with La Rue et al. (20I2), who assessed a 
leadership development program in Kenya by comparing baseline, end-line, and post-intervention data [32]. Our findings also concurred with Rowe et al.'s (20I8) systematic review, which reported professional health care provider practices were improved using multiple strategies rather than by a single strategy [33]. Similarly, Arinez et al (2002) confer that good leadership and management practices improve the work climate, staff satisfaction, motivation and performances [34].

\section{Limitations of the study}

The major limitation of this study is related the employed quasi-experimental study design, unlike randomized study design it is difficult to conclude the causal association between the LMG intervention and the Performance improvements. Despite this limitation, the investigators tried to ensure the relationship through longitudinal follow-up, onsite coaching, and developing agreed action plans. Like many studies, this study has some limitations. The study only targeted LMG training intervention sites, hence, before generalizing, the results, should be interpreted based on the context. In addition, there were a significant number of non-responses among non-trained targeted staff.

\section{Conclusions and recommendations}

The performance of the primary health care entities was significantly improved as a result of enhanced knowledge and skills through LMG trainings, and leadership projects implemented at primary health care entities. We recommend providing LMG trainings for more health workers and managers working at primary health care entities to accelerate implementation of prioritized health sector interventions helpful to achieving the Sustainable Development Goals as a global target. Evaluation of effectiveness and efficiency of the basic LMG training package is recommended.

\section{Abbreviations}

ANOVA: analysis of variance; $\mathrm{CBHI}$ : community-based health insurance; DMR: desired measurable result; FMOH: Federal Ministry of Health; LMG: leadership, management, and governance; SD: standard deviation; SNNP: Southern Nations and Nationalities of Peoples; SPSS: Statistical Package for Social Science; USAID: United States Agency for International Development; VIF: variance inflation factor; WHO: World Health Organization; ZHD: zonal health department.

\section{Declarations}

\section{Acknowledgements}

Transform Primary Health Care Project is a United States Agency for International Development (USAID) funded health program under cooperative agreement number of AID-663-A-17-00002. The program is implemented by a consortium of organizations which includes Pathfinder International, JSI Research \& Training Institute, Inc., EnCompass, Malaria Consortium, Abt Associate Inc., and Ethiopian Midwifes Association in collaboration with local Government and Non-government partners. This technical pre- 
post intervention report is made possible by the generous support of the American people through USAID. The authors' views expressed in this technical report do not necessarily reflect the views of USAID or the United States Government. The investigators are indebted to all participants for their cooperation during data collection. In addition, the investigators are indebted to Heran Demissie for English Language edition.

Funding

\section{None.}

Availability of data and materials

435 The datasets used and/or analyzed during the current study are available from the corresponding author 436 on reasonable request.

437 Authors' contribution

438 The authors of this manuscript are: MDA, BFD, SAM, NT, BBT, WSA, TAB, SSB, DR, \& KE.

439 All authors equally contributed the conception and design of the study, fieldwork, data cleaning, analysis 440 and drafting the manuscript. All authors have read and approved the final document. MDA: the corresponding author submitted the manuscript for publication.

442 Ethics approval and consent to participate

443 The research protocol of was reviewed and ethical clearance was obtained from Amhara Public Health 444 Institute (Ref No. HRTT02/I37/2018, Oromia Regional State Health Bureau (Ref No. BEFO/HBTPH/I445 8/476), SNNP Regional State Health Bureau (Ref No. PLMG-19/8407) and Tigray Regional State Health 446 Bureau (Ref No. 453/I4/8/10) Institution Review Boards and Research Ethics Committee. Oral and 447 written consent was obtained from all research participants. The study had no known risk and no payment 448 was made to participants.

Consent for publication

451 Not Applicable

454 The authors declare that they have no competing interests 
Authors' information

MDA: Ph.D., Senior Health Systems Strengthening Advisor at USAID Transform: Primary Health Care, JSI Research \& Training Institute Inc., Addis Ababa, Ethiopia.

BFD: MPH, Deputy Chief of Party at USAID Transform: Primary Health Care, JSI Research \&Training Institute, Inc., Addis Ababa, Ethiopia.

SAM: MPH, Leadership, Management and Governance Advisor at USAID Transform: Primary Health Care, JSI Research \& Training Institute Inc., Addis Ababa, Ethiopia.

NT: MPH, Federal Ministry of Health, Human Resource Development Directorate Addis Ababa, Ethiopia BBT: Ph.D., Research Advisor at USAID Transform: Primary Health Care, Pathfinder International, Addis Ababa, Ethiopia

WSA: MPH, Health Information System Advisor at USAID Transform: Primary Health Care, JSI Research \& Training Institute Inc., Addis Ababa, Ethiopia.

TAB: MPH, Director, Federal Ministry of Health, Health Extension and Primary Health Services Directorate, Addis Ababa, Ethiopia

SSB, MPH, Federal Ministry of Health, Human Resource Development Directorate Addis Ababa, Ethiopia DR: PhD, JSI Research \& Training Institute, Inc., Boston, USA.

KE: JSI Research \& Training Institute, Inc., Boston, USA.

\section{REFERENCES}

[1] World Health Organization. (2007). Everybody's business--strengthening health systems to improve health outcomes: WHO's framework for action.

[2] World Health Organization. (2005). Strengthening Management in Low-Income Countries. Geneva, Switzerland: WHO.

[3] Mutale W, Vardoy-Mutale AT, Kachemba A, Mukendi R, Clarke K, and Mulenga D. (2017). Leadership and management training as a catalyst to health system strengthening in low-income settings: Evidence from implementation of the Zambia Management and Leadership course for district health managers in Zambia. PloS one, I2(7), e0174536.

[4] Federal Ministry of Health of Ethiopia. (2015); Health Sector Transformation Plan. FMOH: Addis Ababa, Ethiopia.

[5] Management Sciences for Health (MSH). Managers Who Lead: A Handbook for Improving Health Services. Cambridge, MA: Management Sciences for Health, 2005. www.msh.org/resourcecenter/managerswho-lead.cfm (accessed Jan 25, 20I8). 
[6] Chigudu S, Jasseh M, d'Alessandro U, Corrah T, Demba A, and Balen J. (20I4). The role of leadership in people-centered health systems: a sub-national study in The Gambia. Health policy and planning, 33(I), el4-e25.

[7] United States of Agency for International Development: Transform Primary Health Care. (20I7). Cooperative Agreement. USAID Ethiopia.

[8] Rolle IV, Zaidi I, Scharff J, Jones D, Firew A, Enquselassie F, Negash A, Deyessa N, Mitike G, Sunderland N, and Nsubuga P. (20I I). Leadership in strategic information (LSI) building skilled public health capacity in Ethiopia. BMC research notes, 4(I), p.292.

[9] Federal Ministry of Health (FMOH). (20I7). Leadership, Management and Governance In-Service Training Manual for Health Managers at Hospitals and Health Centers. FMOH: Addis Ababa.

[10] Global Health Leadership Institute. (2016). The Primary Health Care Management Development Program. (Participant Manual). New Haven, CT and Addis Ababa, Ethiopia.

[I I] International Institute of Primary Health Care in Ethiopia (IIPHCE) (20I7). Transformation Leadership. Addis Ababa: IIPHCE.

[12] Armstrong M. (2009). Armstrong's handbook of human resource management practice. I Ith edition. KOGAN PAGE: London and Philadelphia.

[13] Creswell JW, and Plano Clark VL. (20I I). Designing and conducting mixed methods research (2nd ed.). Thousand Oaks, CA: Sage.

[14] Bowling A. (20I4). Research methods in health: investigating health and health services. McGraw-Hill Education (UK).

[15] Bullock EP. (2017). An Explanatory Sequential Mixed Methods Study of the School Leaders' Role in Students' Mathematics Achievement through the Lens of Complexity Theory.

[16] Kurt, S. (2016). "Kirkpatrick Model: Four Levels of Learning Evaluation," in Educational Technology, October 24, 2016. Retrieved from https://educationaltechnology.net/kirkpatrick-model-four-levelslearning-evaluation/

[17] Alvarez K, Salas E, and Garofano CM. (2004). An integrated model of training evaluation and effectiveness. Human resource development Review, 3(4), pp.385-4I6.

[18] Federal Ministry of Health of Ethiopia (FMOH). (2016). Health and health related indicators of Ethiopia for the Year 2016/2016.FMOH: Addis Ababa.

[19] USAID Transform: Primary Health Care Project. (2017). Theory of change in practice 20I7. Addis Ababa, Ethiopia.

[20] Tejda JJ and Punzalan JRB. (20I2). On the misuse of Slovin's formula. The Philippine Statistician, 6I(I), Pp. I29-136.

[2I] Pagano M and Gauvereau K. (2000). Principles of Biostatics. 2nd Edition, Duxbury, Pacific Grove. 
[22] Daniel W. (2009). Biostatistics: A Foundation for Analysis in the Health Sciences. 9th Edition, John Wiley and Sons Inc., New York.

[23] Wiseman LM (20II). Evaluating the effectiveness and efficiency of continuous improvement training. Oregon State University (Unpublished master's thesis).

[24] Likert R. (1932). A Technique for the Measurement of Attitudes. Archives of Psychology, I40, I55.

[25] Gershon RR, Stone PW, Bakken S, Larson E. (2004). Measurement of organizational culture and

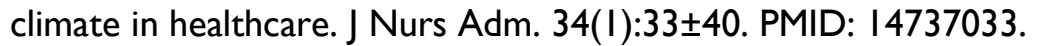

[26] SPSS Inc. , (20II). IBM SPSS Statistics Base 20. SPSS Inc., Chicago.

[27] Menard S. (1995). Applied Logistic Regression Analysis: Sage University Series on Quantitative Applications in the Social Sciences. Thousand Oaks, CA: Sage.

[28] Uneke CJ, Ezeoha AE, Ndukwe CD, Oyibo PG, Onwe FD. (20I2). Enhancing leadership and governance competencies to strengthen health systems in Nigeria: assessment of organizational human resources development. Healthcare policy = Politiques de sante. 7(3):73-84. Epub 2013/02/02. pmid:23372582; PubMed Central PMCID: PMC3298023.

[29] LeMay, Nancy Vollmer, and Alison Ellis, (2007). "Evaluating Leadership Development and Organizational Performance." In the Handbook of Leadership Development and Evaluation. Eds. Kelly M. Hannum, Jennifer W. Martineau, and Claire Reinelt. San Francisco, Calif.: Jossey-Bass, pp. 228-60.

[30] AlYahya MS, Norsiah BM. (20I3) Evaluation of effectiveness of training and development: The Kirkpatrick Model. Asian Journal of Business and Management Sciences 2(I I): I4-24.

[3I] Packard T, Jones L. (2015) An outcomes evaluation of a leadership development initiative. Journal of Management Development 2;34(2):153-68.

[32] La Rue KS, Alegre JC, Murei L, Bragar J, (2012)Thatte N, Kibunga P, Cheburet S. Strengthening management and leadership practices to increase health-service delivery in Kenya: an evidence-based approach. Human resources for health I0(I):25.

[33] Rowe AK, Rowe SY, Peters DH, Holloway KA, Chalker J, Ross-Degnan D. (2018) .Effectiveness of strategies to improve health-care provider practices in low-income and middle-income countries: a systematic review. The Lancet Global Health I;6(I I):el I63-75.

[34] Arinez A, Bouzidi M, Koo B, Sayeed A, Serenata C, Suarez E, Sulaiman AB.(2002). Creating a Work Climate That Motivates Staff and Improves Performance. The Manager Journal I I (3). 


\section{Legend}

A conceptual map adopted to evaluate the Leadership, Management and Governance Trainings in Ethiopia. The framework depicts to the relations of self-efficacy, cognitive and training performance with individual and organizational factors in contributing for better health outcome.

Figure 2.: Map of Ethiopia showing USAID Transform Primary Heath Care project supported woredas.

598

599

600

601

Map of Ethiopia depicting the USAID Transform: PHC project supported woredas. The green colored woredas are high performers, yellow colored woredas are medium performers and red colored woredas are low performers in terms of maternal and child health indicators.

Figure 3: Proportion of health service coverage change of I 36 leadership projects by program category, September 2018.

Bar chart showing eight major performance improvement projects developed by 136 core LMG teams and the average proportion on the baseline and end-line results.

Figure 4: Certification of Trainees $^{2}$ after evaluation using posttest scores (Theory) and end-line leadership project performance assessment, September 2018.

Bar chart showing the proportion of basic LMG trainees who complete the training using the criteria of post test scores, and performance improvement achievement by training approaches.

Table I. Participants trained According to the Two Models of LMG, by Region and Sex, September 2018

The number of Leadership, Management and Governance trainees by region and training approaches.

Table 2: Socio-demographic characteristics of basic LMG for health facility manager trainees $(n=292)$, September 2018

The socio-demographic characteristics of Basic LMG trainees enrolled in this research.

Table 3: Socio-demographic characteristics of non- trained staff $\left(n_{1}=333\right)$ and targeted health facilities $\left(n_{2}=136\right)$, September 2018

The socio-demographic characteristics of non- trained staff in LMG intervention facilities, who participated in this research. In addition, the table presents the characteristics of selected LMG intervention primary health care entities.

Table 4: Work climate, management system strength, and ability to respond to challenges before and after assessment by LMG trained and non-trained staff, September 2018

\footnotetext{
${ }^{2} 115$ people attended block LMG training; 138 attended segmented I approach, and 40 attended segmented II approach.
} 
621 The mean and standard deviation scores on perceived work climate, management system and responsiveness to 622 changes by trained and non-trained staffs.

\section{Box I: Sample Questionnaire}

624 The box presents sample items from composite scales representing the three categories namely, management 625 system, work climate, and responsiveness.

626 

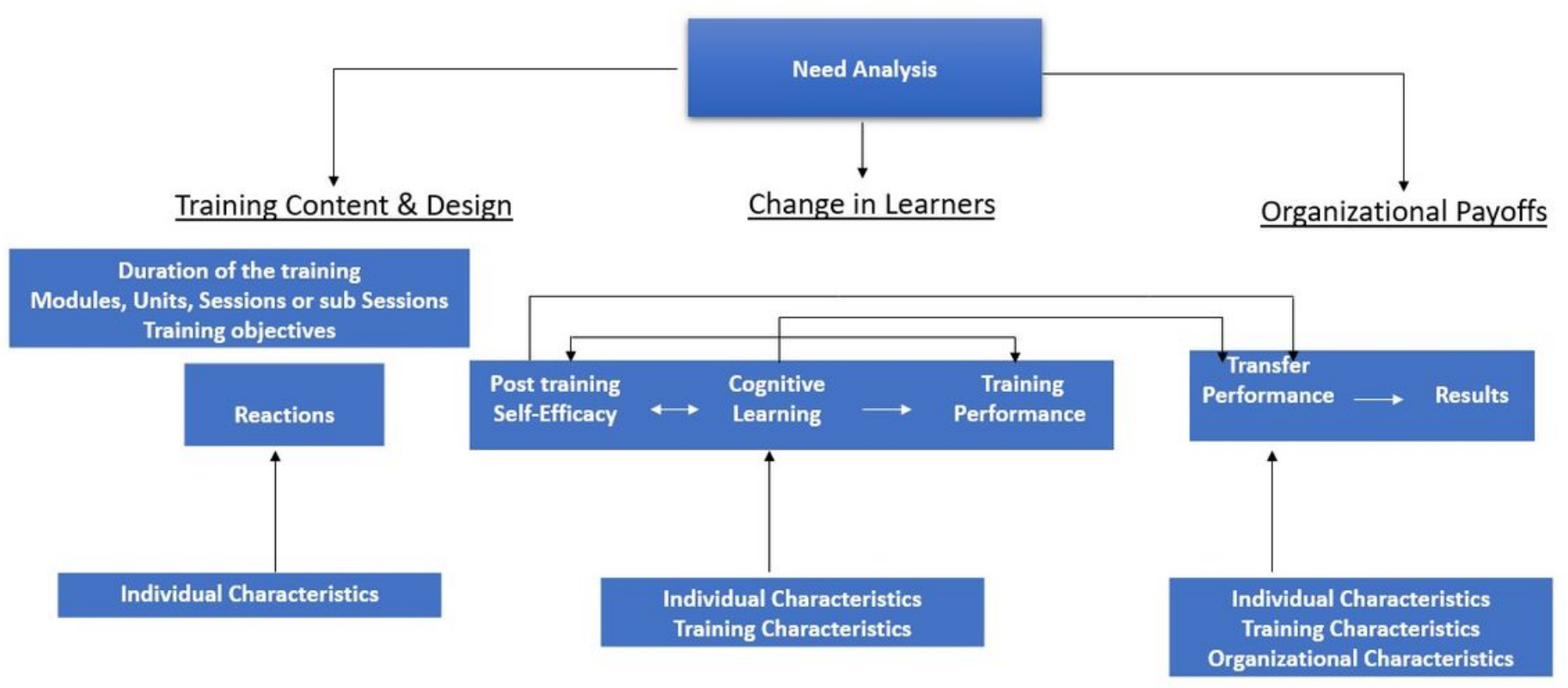

Figure 2

Conceptual Map of LMG Training Evaluation [12], [16] A conceptual map adopted to evaluate the Leadership, Management and Governance Trainings in Ethiopia. The framework depicts to the relations of self-efficacy, cognitive and training performance with individual and organizational factors in contributing for better health outcome. 


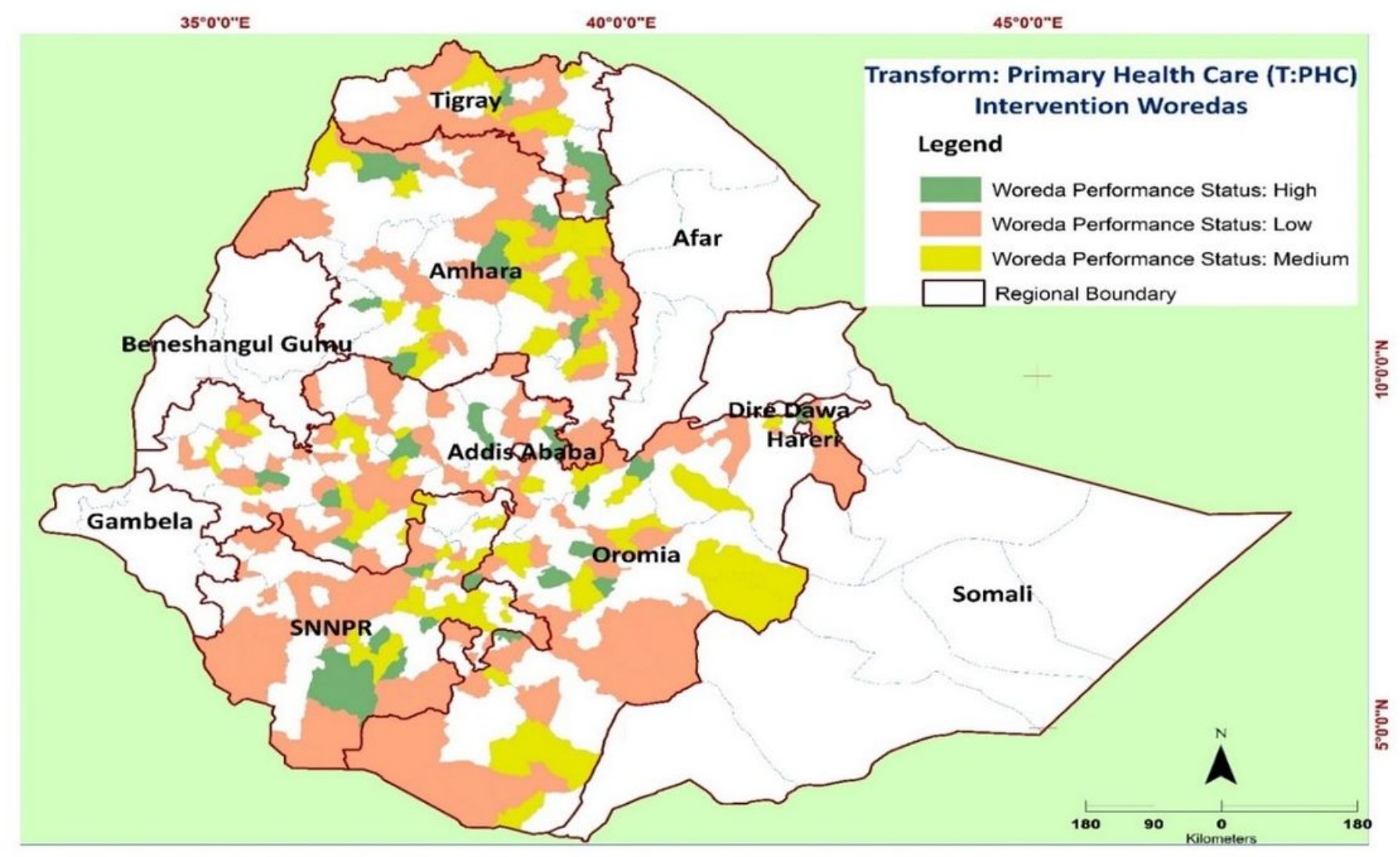

\section{Figure 4}

Map of Ethiopia showing USAID Transform Primary Heath Care project supported woredas. Map of Ethiopia depicting the USAID Transform: PHC project supported woredas. The green colored woredas are high performers, yellow colored woredas are medium performers and red colored woredas are low performers in terms of maternal and child health indicators. 


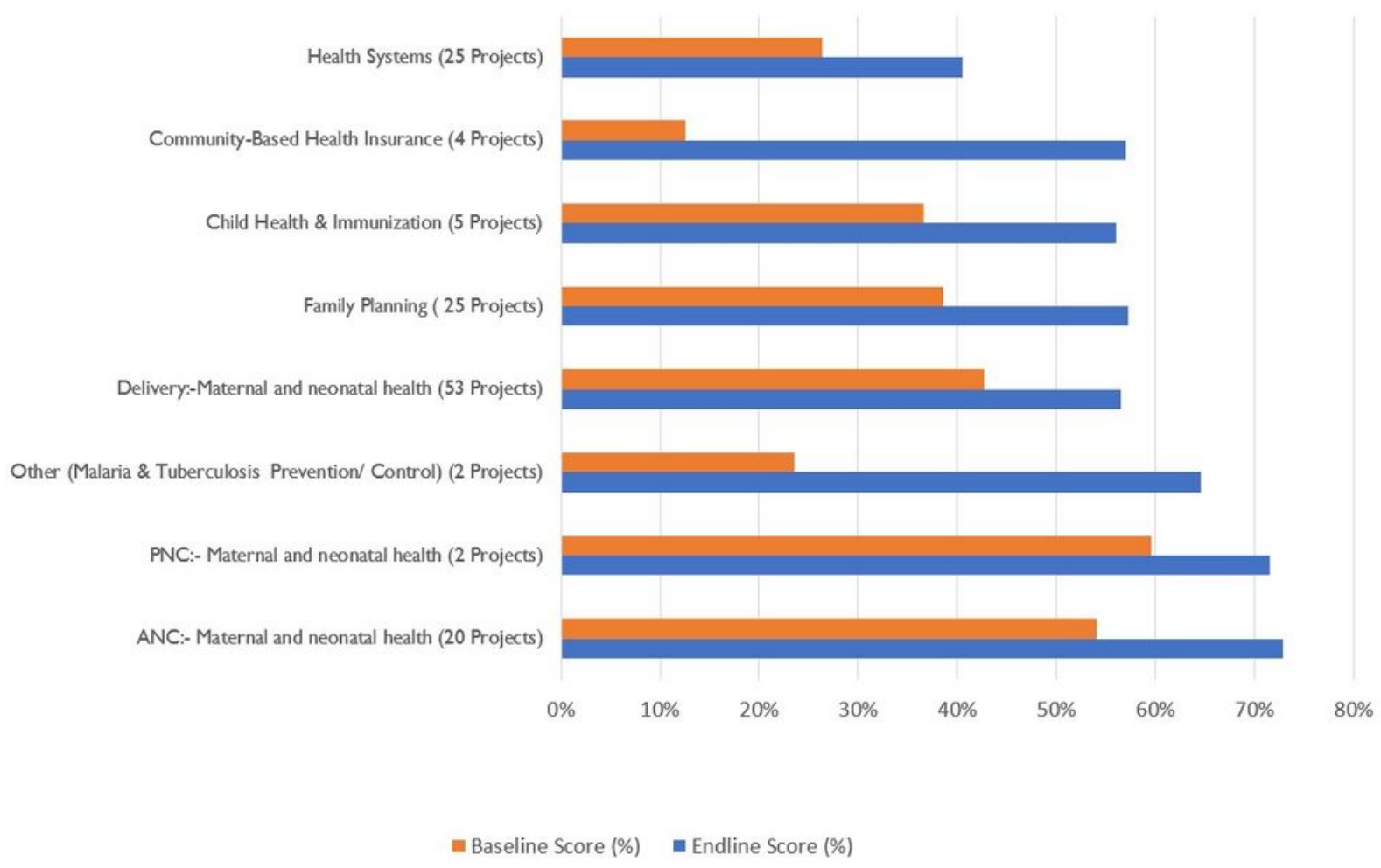

\section{Figure 6}

Proportion of health service coverage change of 136 leadership projects by program category, September 2018. Bar chart showing eight major performance improvement projects developed by 136 core LMG teams and the average proportion on the baseline and end-line results. 


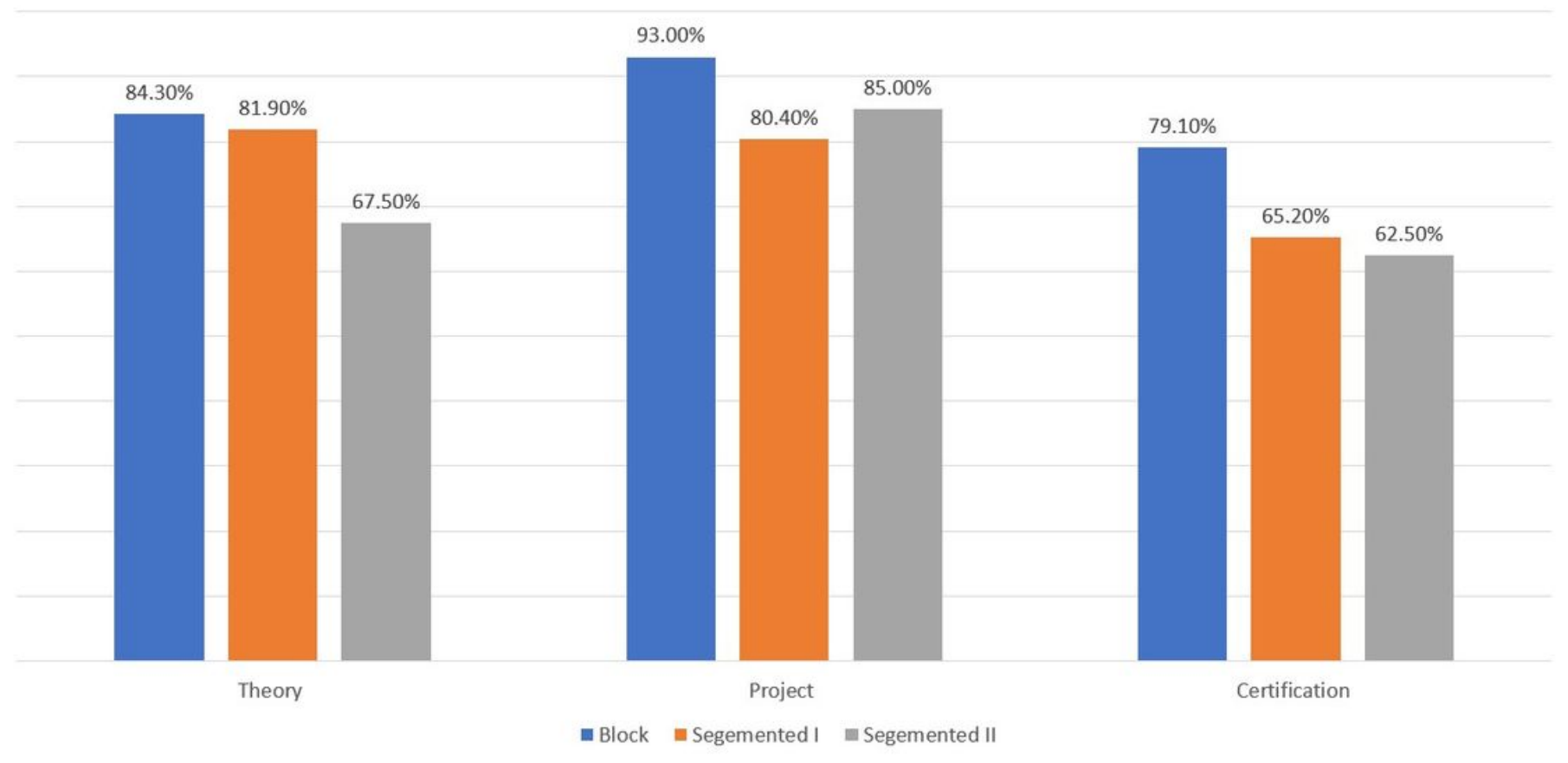

Figure 8

Certification of Trainees after evaluation using posttest scores (Theory) and end-line leadership project performance assessment, September 2018.

\section{Supplementary Files}

This is a list of supplementary files associated with this preprint. Click to download.

- Additionalfile2.docx

- Box1.pptx

- Additionalfile2.docx

- Additionalfile1.docx

- Additionalfile1.docx

- Box1.pptx 